\title{
OXYTOCIN REQUIREMENTS AT C-SECTION FOR FAILURE TO PROGRESS IN LABOR
}

Mrinalini Balki MD*, Michael Ronayne MD*, Sharon Davies MD*, John Kingdom MD\# , Rory Windrim MD\# ,Jose CA Carvalho MD PhD*\# , Department of Anesthesia and Pain Management* and Department of Obstetrics and Gynecology\# ,Mount Sinai Hospital and University of Toronto, 600 University Avenue room 1514, Toronto, Ontario, M5G 1 X5.

INTRODUCTION: Oxytocin is administered at C-section (CS) to reduce blood loss. Serious side effects have been documented with large doses or rapid boluses. The purpose of this study was to estimate the minimum dose of oxytocin required to produce effective uterine contraction $\left(\mathrm{ED}_{90}\right)$ at $\mathrm{CS}$ following failure to progress in labor.

METHODS: With REB approval and informed consent, a randomized, single-blinded study was conducted in 30 parturients undergoing CS for failure to progress in labor, under epidural anesthesia. Oxytocin was administered as bolus after fetal delivery (initial dose), according to a biased coin up-down sequential allocation scheme with increments/decrements of $0.5 \mathrm{IU}$ (starting dose $0.5 \mathrm{IU}$ ). Additional boluses of $0.5 \mathrm{IU}$ were administered if required (total dose). Uterine contraction and intra-operative complications were recorded. Blood loss was estimated (EBL) based on hematocrit changes.

RESULTS: All patients received oxytocin during labor (maximum dose $10.3 \pm 8.1$ $\mathrm{mIU} / \mathrm{min}$ and duration of infusion $9.7 \pm 6.4$ hours). The $\mathrm{ED}_{90}$ of oxytocin at CS was 2.99 $\mathrm{IU}(\mathrm{SE}=0.34,95 \% \mathrm{CI}=2.32-3.67)$. The $\mathrm{EBL}$ was $1178 \pm 716 \mathrm{ml}$. There was no significant association between the initial dose of oxytocin at CS and EBL $(\mathrm{p}=0.11)$. There were no significant correlations between the time required for effective uterine contraction or the total dose of oxytocin at CS and the duration of oxytocin infusion during labor $(\mathrm{p}=0.98$ and 0.49 ) or the maximum oxytocin dose used for augmentation of labor ( $\mathrm{p}=0.80$ and 0.67). Post-delivery complications included hypotension $30 \%$, tachycardia $30 \%$, nausea $60 \%$, vomiting $40 \%$ and flushing $40 \%$. In all cases the uterus was exteriorized for repair.

DISCUSSION: The effective bolus dose of oxytocin at CS for failure to progress in labor can be lower than those currently recommended. However, this dose is much larger than that required at elective $\mathrm{CS}\left(\mathrm{ED}_{90}=0.35 \mathrm{IU}\right)^{1}$, likely secondary to oxytocin receptor desensitization due to prolonged oxytocin exposure during labor ${ }^{2}$. Patients not responding to such doses should be considered for other uterotonic agents, not only to avoid oxytocin side effects, but mainly to provide effective control of blood loss and prevent post-partum hemorrhage.

REFERENCES: 1. Obstet Gynecol. 104:1005-1010; 2. Am J Obstet Gynecol.18 8 497502 